\title{
Design and Implementation of Real Time Monitoring and Control System for Distributed Robotic Systems Supported with IOS/Android Application
}

\author{
Mehmet Fatih IŞIK, Mustafa Reşit HABOĞLU, Cemal YILMAZ, Ercan Nurcan YILMAZ
}

\begin{abstract}
In this study, a real time monitoring and control of the working parameters of distributed robotic systems used in manufacturing processes is presented. Additionally, a fault diagnosis and protection system is developed in the control and monitoring system to prevent possible errors during the working process. Unlike the conventional monitoring and control systems, Android/IOS based smart phones and tablets are used besides SCADA and the process is supported by cameras. 3 different robotic systems are used in the study and electrical, electronic and mechanical prototypes are designed for each of them. Thus, a complete robotic system being able to perform real time monitoring and control for industrial manufacturing processes that is supported by smart phone applications and fault diagnosis and protection system is developed successfully.
\end{abstract}

Keywords: distributed robotic systems; monitoring and control; PLC; robot arm

\section{INTRODUCTION}

The industrial manufacturing can be described as a process consisting of several procedures. Those procedures are monitored and controlled with various techniques. The real time monitoring and control of those procedures which work as distributed systems is an important fact. Technological developments provide the opportunity for real time monitoring and control of industrial manufacturing processes $[1,2]$. One of the important parts of manufacturing processes is robotic systems which are developed with the combination of mechanical and electrical systems. Robotic systems consist of various mechanical designs. Using electrical motors is the common feature for any robotic system. Advanced motor control systems are generally based on motor drivers so that the motors are controlled by changing the driver parameters. An efficient manufacturing process is possible with the monitoring and control of the driver parameters which also provides the opportunity to predict any possible error during the operation.

The need to reduce the human factor during manufacturing processes brings the requirement for remote monitoring and control systems [1]. Various techniques are applied for monitoring and control of robotic systems [3-8]. The main purpose of those techniques is to obtain fast, reliable and efficient manufacturing processes. For this reason, conventional monitoring and control techniques are substituted by modern and smart systems [9, 10]. There are several studies in the literature that investigate modern monitoring and control systems [11-15]. Those studies generally focus on the monitoring and control of a single system. However, a manufacturing process of a product consists of many procedures. For this reason, monitoring and control of all the procedures at the same time is an important fact for the process to be completed successfully.

The robotic systems are widely used especially for the distributed work spaces in ceramic manufacturing factories. There are different types of motors such as step motors, servo motors and asynchronous motors that are used in robotic systems. There ought to be a real time monitoring and control system for those motors. That is important for the efficiency of the manufacturing process.

The aim of this study is to develop real time monitoring and control of robotic systems used in manufacturing processes. The developed system can perform monitoring and control for a distributed robotic system at the same time. The studies regarding this issue only focus on the design of the monitoring system. Those systems are generally performed by monitoring the parameters in CPU or using camera systems. In such systems, there is no possibility to intervene in the system in the situation of fault detection. This study includes both manual and automatic fault detection and protection system besides the monitoring of the whole system. Another important part of the study is the use of IOS/Android application to monitor and control the process.

This study consists of three main parts. First part focuses on the hardware configurations regarding the robotic systems, second part contains the developed software and in the third part, IOS/Android applications are presented.

\section{SYSTEM ARCHITECTURE \\ 2.1 Development of Axis Control}

In a typical servo system, drivers take the inputs (velocity, position, direction etc.) to control the motors. Inputs are obtained from the controllers. According to the working situation, there are various feedback signals for the controllers to process and generate the necessary signals $[16,17]$. This procedure needs to be done in a very short time. For this reason, the speed of the communication between the controllers, drivers and user interface systems is an important fact.

In this study, SCADA and Smart Phone are used for the user control while PLC (Programmable Logic Controller) is used as the controller. To increase the speed of the communication between PLC and SCADA, an open domain web named Device-Net is used. Besides its fast communication speed at short distances, Device-Net protocol is preferred also for its low cost of maintenance 
because of the less amount of cable usage. Additionally, it is suitable with many devices that are used in industrial applications. The functional diagram of the axis monitoring and control system is presented in Fig. 1.

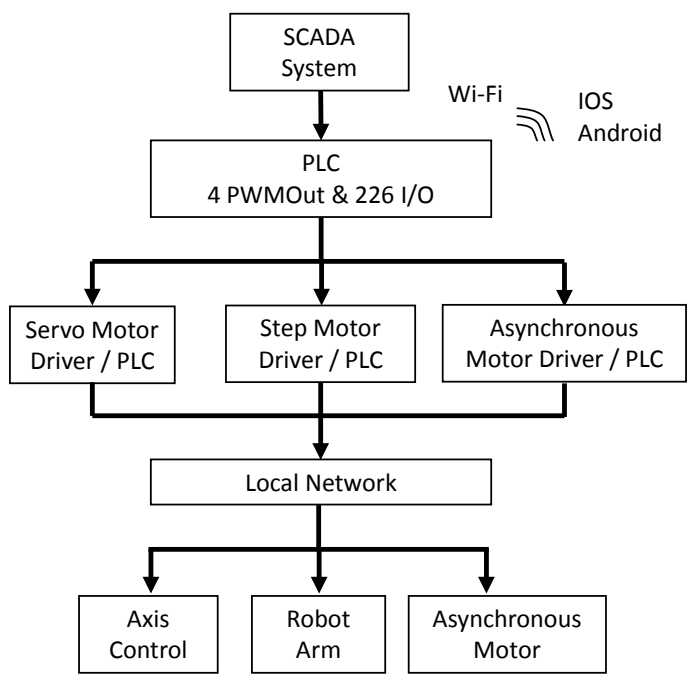

Figure 1 Functional diagram of monitoring and control

In this study, an Omron CX-Programmer is used for the programming of the Omron CJ2M-CPU31 PLC that consists of 16 digital input and 32 digital output. That PLC gathers the data from the SCADA through DeviceNet protocol and sends the proper signal to the data bus to activate the axis control accordingly. Lastly, the signal is transmitted to the servo drivers (Omron R88D-KT04H) and servomotors (Omron $\mathrm{K} 40030 \mathrm{H})$. The data acquisition is provided by a USB port connection. The servomotor control process can be seen in Fig. 2.

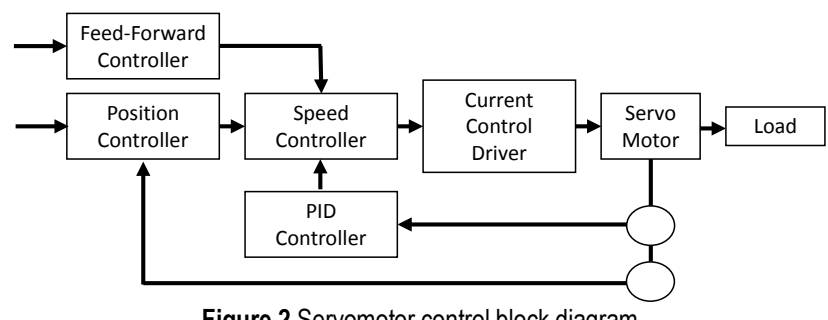

Figure 2 Servomotor control block diagram

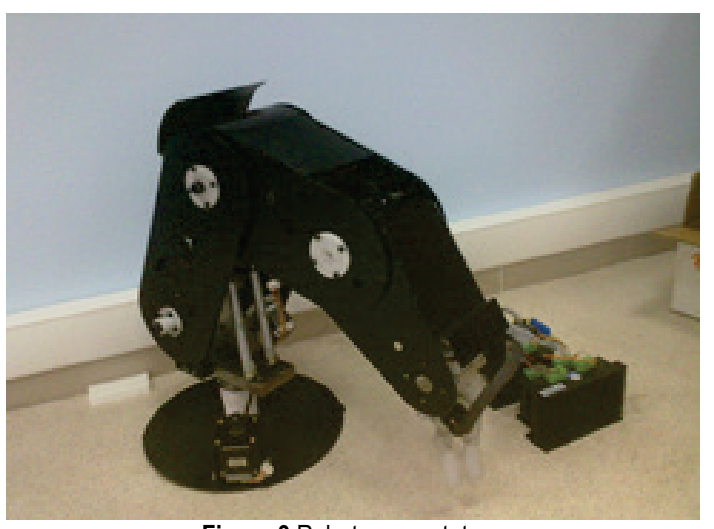

Figure 3 Robot arm prototype

\subsection{Robot Arm Design and Control Unit 2.2.1 Robot Arm Design}

A six degrees of freedom robot arm is designed and built as a prototype. The joints are connected to each other by using a belt-wheel system. There are reduction gears at the joints that have high couples. The sketching of the parts is done via AutoCad. Fig. 3 shows the prototype of the robot arm.

\subsubsection{Robot Arm Control Unit}

In recent years, traditional systems have been substituted by servo motors and step motors due to their programmability and sensitivity [18]. For small systems that do not require high torques and speeds, step motors are preferred for their easy controllability and low cost. The method is the same as the one shown in Fig. 1.

The control system consists of three main components such as (i) PLC (the same model that is used in axial control), (ii) step motor and driver circuit and (iii) SCADA and smart phone software.

PLC is a control system that has input and output units and user interface that provide remote controlling of industrial automation systems [16, 19-25].

\subsection{Asynchronous Motor}

Alternating current asynchronous motors are multi variable, strong couple, nonlinear and time varying systems [26]. Therefore, asynchronous motors are the most common motor types used in industrial applications [27]. In this study, a PLC, a 3 phase asynchronous motor and a frequency converter are used. Fig. 4 shows the block diagram of the system.

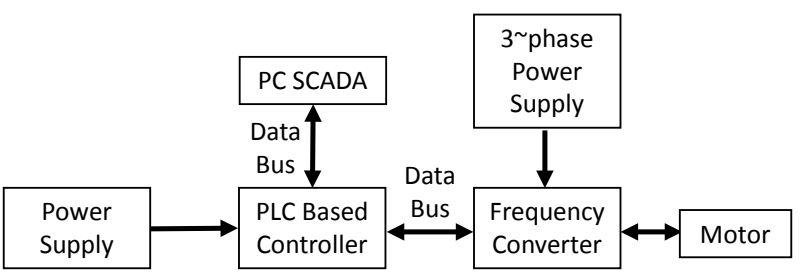

Figure 4 Block diagram of the asynchronous motor control system

The same PLC from the robot arm control system is used. The specifications of the PLC can be found in the previous section.

The 3 phase asynchronous motor has a star connection, 3.6 A of rated current, $380 \mathrm{~V}$ of input voltage and $3000 \mathrm{rpm}$ rotation capacity.

The frequency converter type is A4022EE from speed controller series of Omron $3 \mathrm{G} 3 \mathrm{RX}$. It has a frequency range of $0-400 \mathrm{~Hz}$.

\section{SOFTWARE METHODOLOGY FOR MONITORING, CONTROL AND PROTECTION}

In this section, the software units and flow diagrams used in the development of computer interface for the control, monitoring and protection with the data acquisition between the hardware system components are described. Several facts such as fast and reliable data transfer, ability to present data as graphs and flexible memory and monitoring are taken into account for the selection of software units. The flow diagram for monitoring, control and protection system is presented in Fig. 5. As seen in the figure, the optimum parameters are compared with the system parameters to obtain an automatic protection system. 


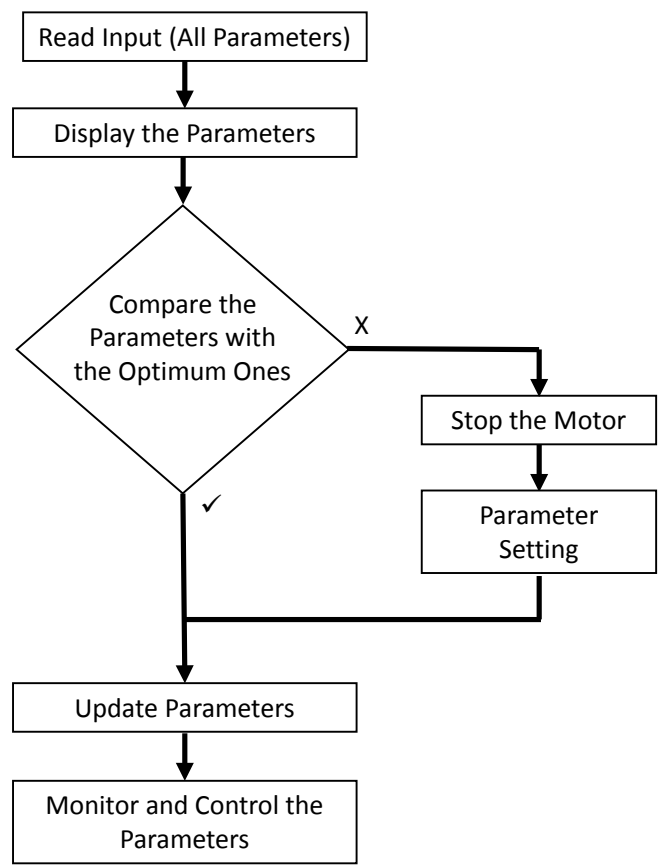

Figure 5 Protection, control and monitoring algorithm

\subsection{PLC Software}

The PLC model used in the system is controlled with CX-Programmer. Fig. 6 shows the software algorithm.

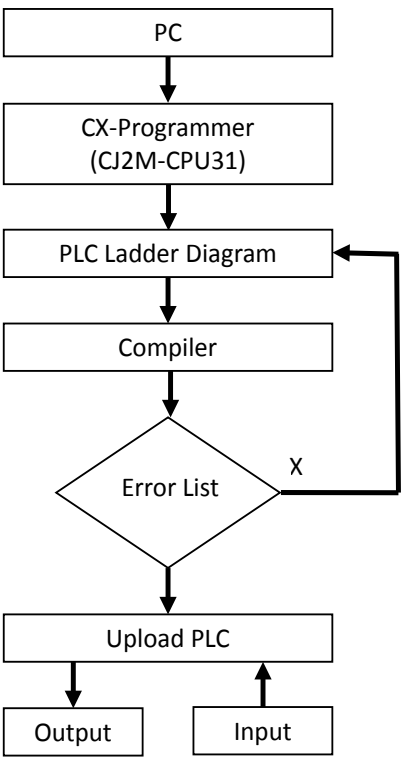

Figure 6 Block diagram of the PLC software algorithm

According to Fig. 6, the ladder diagram which is developed via CX-Programmer is loaded to the disc during the PLC programming. The loaded program is compiled later. If there is an error in the program code during the operation, a file named "ERR" is generated. Otherwise, the program code is uploaded to the PLC via USB port.

There are three different algorithms developed inside the PLC. The I/O systems that are digitally programmed inside the PLC activate the desired algorithm according to the independent working requirement. Thus, the units can operate independently.

\subsection{SCADA Software}

SCADA (Supervisory Control and Data Acquisition) is a data acquisition and observation system [28]. Omron CX-Supervisor is used to develop the SCADA software. 3 different interface screens are constituted based on the prototype model. Monitoring, control and protection fields are integrated to the interface screen through the SCADA software. Fig. 7 shows the block diagram of the developed SCADA software.

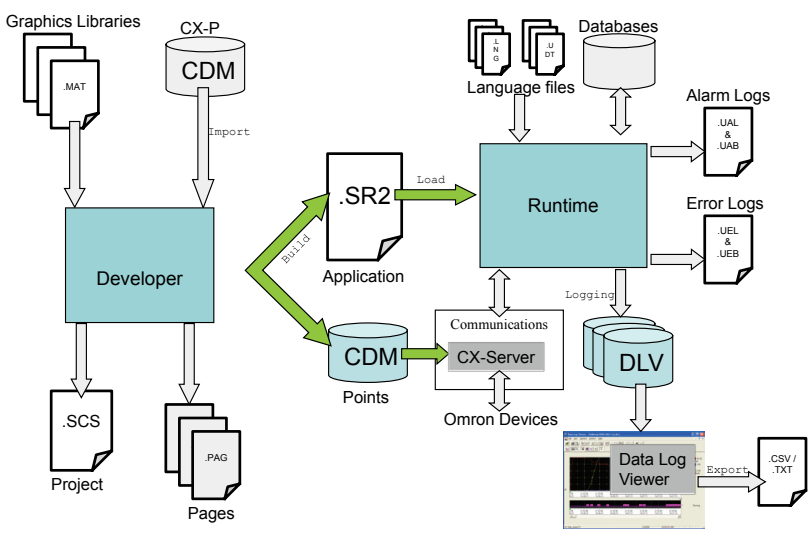

Figure 7 Block diagram representing the SCADA software

\subsection{Smart Phone Software}

The monitoring and control screen is designed via the software program called EasyBuilder-Pro. The screen and the PLC models are chosen prior to starting the design. The communication with PLCs is obtained with Ethernet connection.

The monitoring and control of the screen is uploaded to a server device named CMT-SVR which is connected to an access point for a wireless communication. Thus, this screen is available to reach for an IOS/Android device (smart phone or a tablet) having the application named CMT-Viewer. The control and monitoring of whole system can be obtained by just using that application.

\section{APPLICATIONS}

In this section, the software examples developed for smart phone applications via CX-Supervisor are presented.

\subsection{SCADA Applications}

The parameters that are received previously and transmitted to the addresses as categories can be monitored and controlled with SCADA screen as seen in Fig. 8. The user can perform an operation to parameters that belong to a selected category while also being able to control all the categories at the same time.

Fig. 8 represents the SCADA application software for monitoring, control and protection of the parameters that belong to 3 phase asynchronous motor. The same system is developed for the other prototypes, which is shown in Fig. 9 and Fig. 10 for axial control and robot arm respectively. The main purpose is to allow user to monitor the situation for any desired process in real time. 
Moreover, the user is also authorized to change any parameter at will.

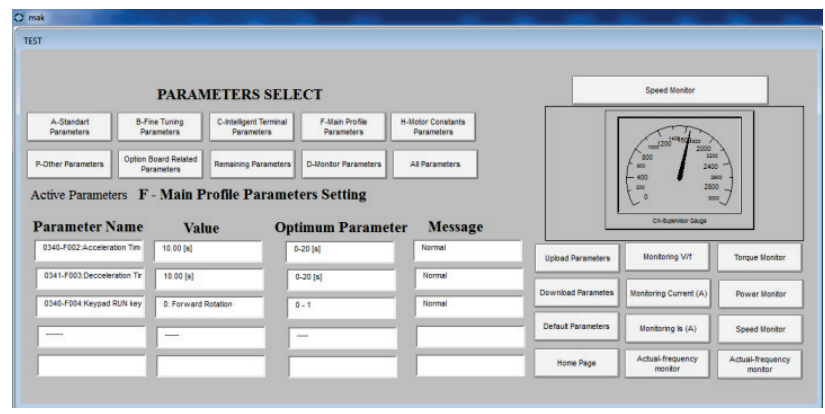

Figure 8 Parameter selection and monitoring screen

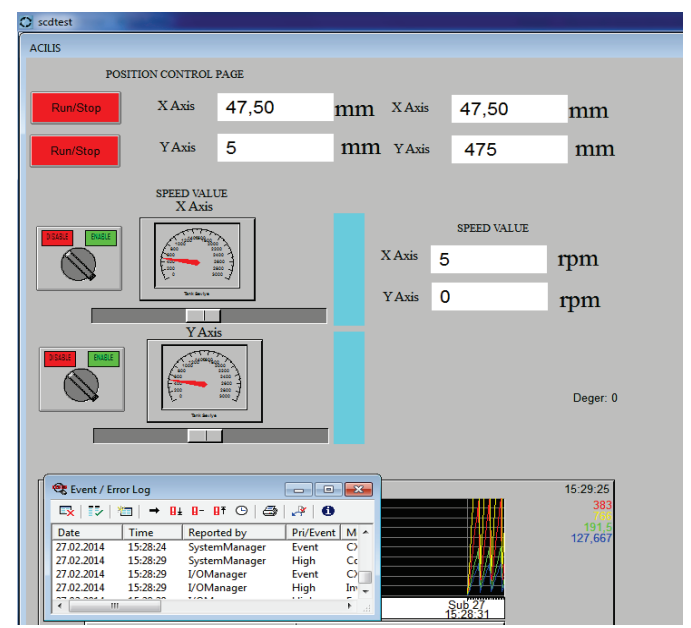

Figure 9 The position control for the axis

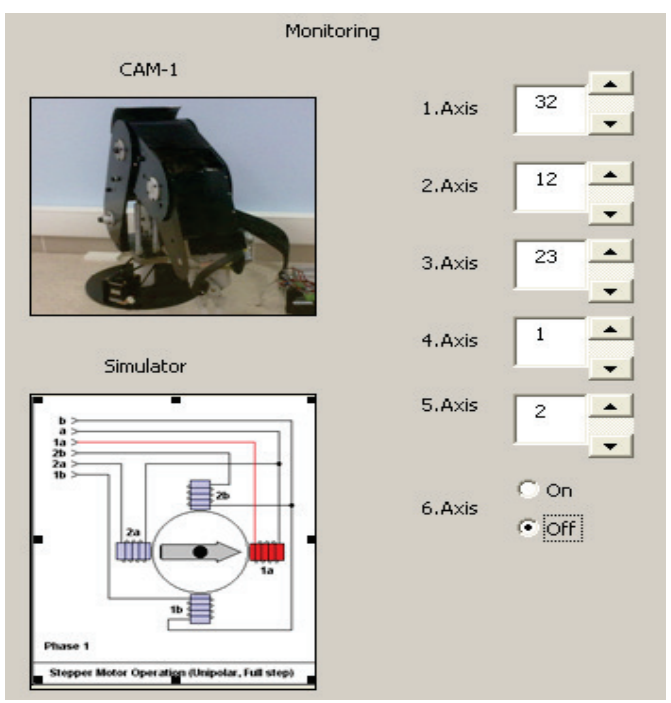

Figure 10 Monitoring and control screen for robot arm

\subsection{IOS/Android Applications}

Firstly, the software program called CMT-Viewer is downloaded from the application stores of IOS/Android systems. CMT-Viewer screen is presented in Fig. 11. There are six server devices used in this study.

The settings of each device seen in Fig. 11 ought to be organized to set the addresses of the channels of Ethernet 1 and 2. The IP address of the CMT-SVR, which is the server device, is set to 192.168.0.100 while address of Ethernet 2, which allows the communication with PLC, ought to be set carefully. The PLC IP address used in this study is 192.168.250.1. Therefore, the IP address of Ethernet 2 is set as a static IP having the number of 192.168.250.32. Thus, the communication between CMTSVR and PLC is obtained. If there is a mistake during the settings of those IP addresses, screen will display a communication error message.

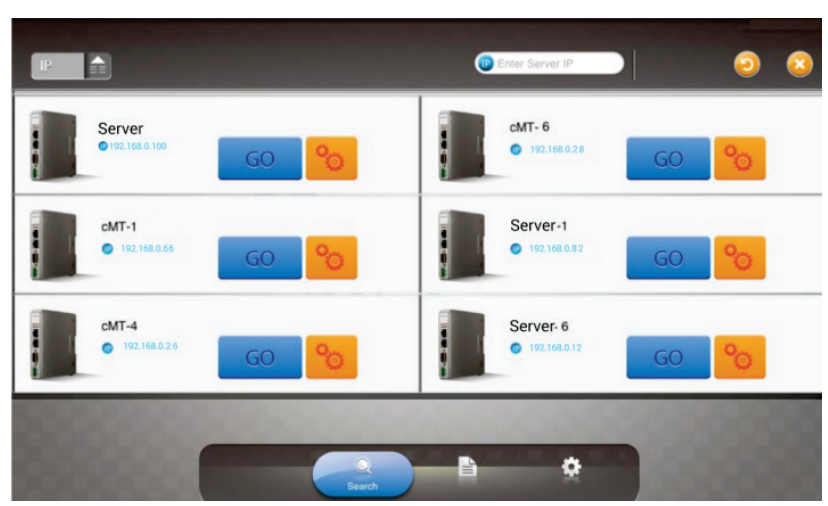

Figure 11 IOS/Android access screen

Once the required address settings are complete, server devices can be reached by clicking the "GO" button as seen in Fig. 11.

After the loading process, the monitoring screens for the axis control system, robot arm and asynchronous motor prototypes are shown in Fig. 12, Fig. 13 and Fig. 14 respectively. Besides the monitoring of the parameters, the user can also control and set new parameter values in real time via those screens.

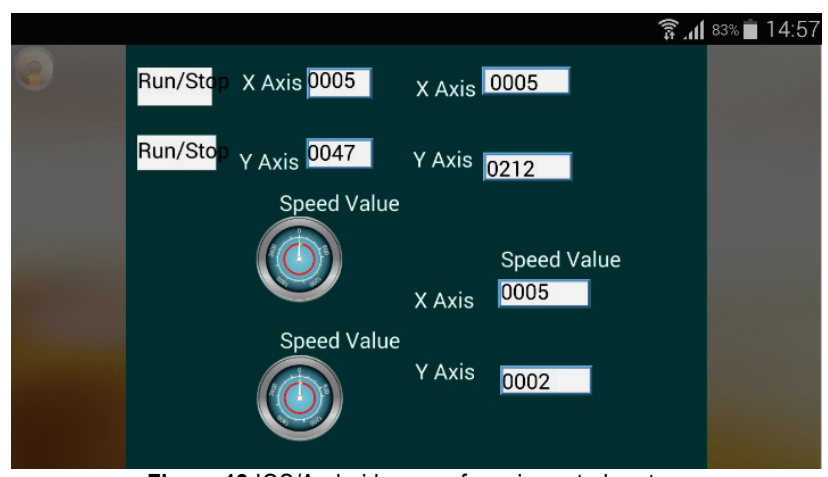

Figure 12 IOS/Android screen for axis control system

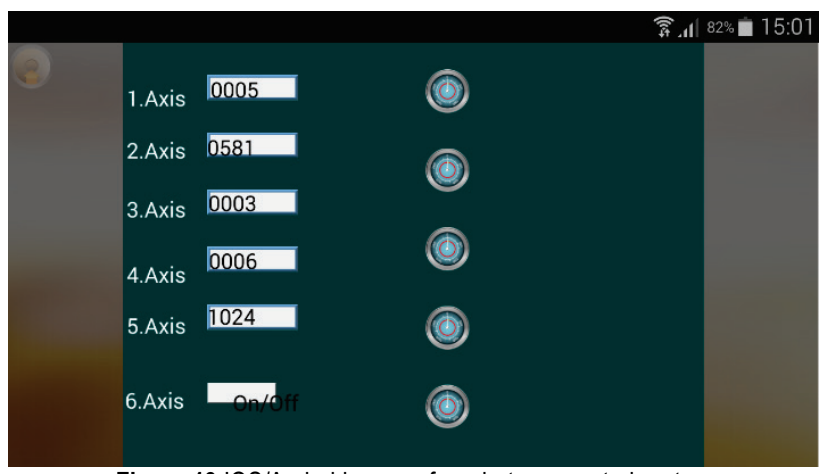

Figure 13 IOS/Android screen for robot arm control system

The system displays an error message if there is a connection problem or during a program modification. Fig. 15 shows an example of the error message.

The general view of the prototypes constituting the asynchronous motor control system is presented in Fig. 16. 


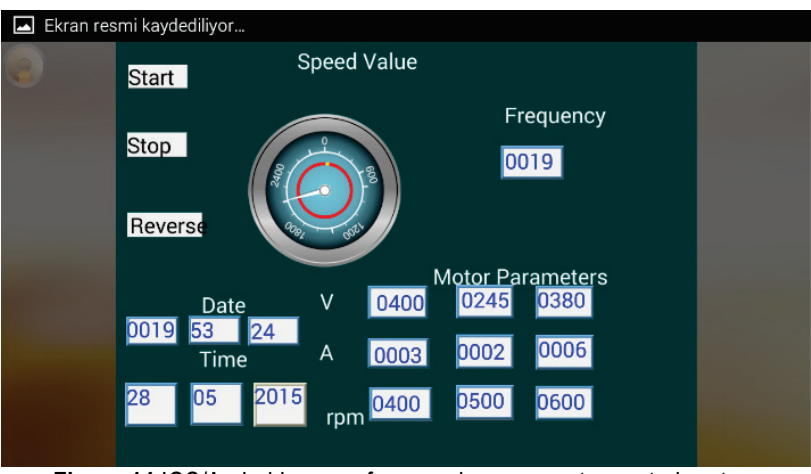

Figure 14 IOS/Android screen for asynchronous motor control system

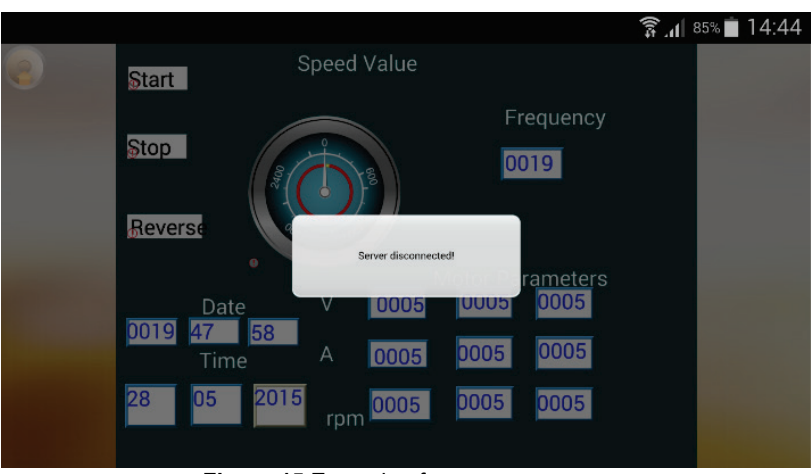

Figure 15 Example of an error message

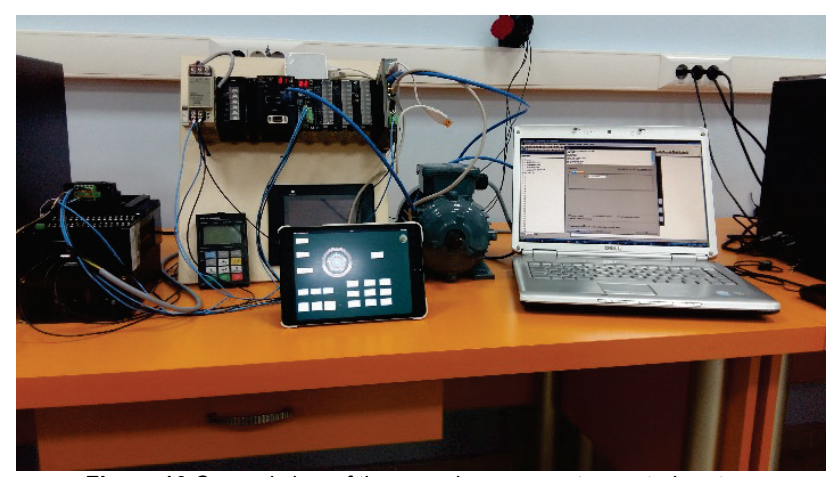

Figure 16 General view of the asynchronous motor control system

\section{CONCLUSION}

In this study, a web based monitoring, control and protection of the driver parameters of distributed robotic systems used in industrial manufacturing processes is developed successfully. The developed application is also important for the fault detection and protection for such systems. In a typical robotic system, possible errors are related to electrical motors. Therefore, it is important to observe and analyse all the processes. The SCADA software developed in this study presents a solution for the issue. A successful system is established for the real time monitoring, control and protection of all the processes. Additionally, the system is supported with IOS/Android based smart phones and tablets which are one of the important features of technology. Therefore, this study eliminates the requirement for user to spend time around CPU and brings mobility to the process.

The developed system can either be used for education purposes or experimental studies in institutions.

The necessary arrangements and modifications to the software can provide monitoring and control of any system at desired specifications.

\section{Acknowledgements}

This article is a revised and expanded version of a paper entitled "Design and implementation of real time monitoring and control system for robot arms used in industrial applications" presented at $15^{\text {th }}$ International Conference on Robotics, Control and Manufacturing Technology which was held in Kuala Lumpur/Malaysia at April 23-25 ${ }^{\text {th }}, 2015$ [24].

\section{REFERENCES}

[1] Wen, J. S., Te-Jen, S., \& Chia-Ming, L. (2012). Development of remote monitoring and control system based on PLC WebAccess for learning mechatronics. International Journal of Advanced Robotic Systems, 1-7.

[2] Ciufudean, C. \& Neri, F. (2014). Open research issues on multi-models for complex technological systems. WSEAS Transactions on Systems, 13

[3] Saygin, C. \& Kahraman, F. (2004). A web-based programmable logic controller laboratory for manufacturing engineering education. International Journal of Advanced Manufactured Technology, 24, 590-598. https://doi.org/10.1007/s00170-003-1787-7

[4] Mougharbel, I., Hajj, A. E., Artail, H., \& Riman, C. (2006). Remote lab experiments models: A comparative study. International Journal of Engineering Education, 22(4), 849-857.

[5] Hui, W., Hu, P. J. H., Clark, T. H. K., Tam, K. Y., \& Milton, J. (2008). Technology-assisted learning: A longitudinal field study of knowledge category learning effectiveness and satisfaction in language learning. Journal of Computer Assisted Learning, 24, 245-259. https://doi.org/10.1111/j.1365-2729.2007.00257.x

[6] Siddique, A., Yadava, G. S., Singh, B. (2005). A review of stator fault monitoring techniques of induction motors. IEEE Trans. Energy Convers, 20(1), 106-114. https://doi.org/10.1109/TEC.2004.837304

[7] Zhongming, Y. \& Bin, W. (2000). A review on induction motor online fault diagnosis. In: Zhao Zhengming, Jiang Xiaohua, Huang Lipei, editors. The $3^{\text {rd }}$ International Power Electronics and Motion Control Conference, Aug 15-18, 2000, Beijing / China. China: International Academic Publishers, 1353-1358.

https://doi.org/10.1109//PEMC.2000.883050

Benbouzid, M. E. H. (1999). Bibliography on induction motors faults detection and diagnosis. IEEE Trans. Energy Convers, 14(4), 1065-1074. https://doi.org/10.1109/60.815029

[8] Yilmaz, C., Gurdal, O., \& Kosalay, I. (2010). Network induced delay of asynchronous motor connected to profibus-dp network using fuzzy logic control algorithm. Expert System with Applications, 37(32), 3248-3255. https://doi.org/10.1016/j.eswa.2009.09.055

[9] Yildiz, C. \& Ozcalik, R. H. (2008). Genetik algoritma destekli bulanik denetim kullanarak vektor esasli asenkron motor kontrolu [thesis]. Kahramanmaras: Kahramanmaras Sutcu Imam University.

[10] Yao, A. W. L. \& Ku, C. H. (2003). Developing a PC-based automated monitoring and control platform for electric power systems. Electr. Power Syst. Res., 64, 129-136. https://doi.org/10.1016/S0378-7796(02)00150-5

[11] Avlonitis, D., Kouroumbas, K., \& Vlachakis, N. (2004). PC-based SCADA system and additional safety measures for small desalination plants. Desalination, 165, 165-176. https://doi.org/10.1016/j.desal.2004.06.019

[12] Patel, M., Cole, G. R., Pryor, T. L., \& Wilmot, N. A. (2004). Development of a novel SCADA system for laboratory testing. ISA Trans., 43, 477-490. https://doi.org/10.1016/S0019-0578(07)60162-1 
[13] Salihbegovic, A., Marinkovic, V., Cico, Z., Karavdic, E., \& Delic, N. (2009). Web based multilayered distributed SCAD/HMI system in refinery application. Comput. Stand Interfaces, 31, 599-612. https://doi.org/10.1016/j.csi.2008.03.023

[14] Ozdemir, E. \& Karacor, M. (2006). Mobile phone based SCADA for industrial automation. ISA Trans., 45, 67-75. https://doi.org/10.1016/S0019-0578(07)60066-4

[15] Isik, M. F., Haboglu, M. R., \& Yanmaz, H. (2014). Monitoring and control of PLC-based motion control systems via Device-Net. In: $16^{\text {th }}$ International Power Electronics and Motion Conference and Exposition, IEEE, September 21-24, Antalya / Turkey, 963-966. https://doi.org/10.1109/EPEPEMC.2014.6980632

[16] Coskun, I. \& Isik, M. F. (2004). Servo motorun mikrodenetleyici ile konum ve hiz denetimi. Gazi Universitesi Fen Bilimleri Enstitusu Dergisi, 13(3), 115125.

[17] Sahbaz, H., Karagulle, H., \& Malgaca, L. (2007). Bir hegzapod uygulamasinda bilgisayar tabanli hareket. In: 13 . Ulusal Makina Teorisi Sempozyumu, June 7-9, Sivas / Turkey, 241-251.

[18] Isik, M. F. \& Coskun, A. (2008). Bilgisayar destekli elektrik makinalari egitimi. In: International Conference on Educational Sciences, Eastern Mediterranean University, June 23-25, Famagusta / North Cypru, 1016-1021.

[19] Coskun, I., Isik, M. F., \& Yanmaz, H. (2008). PLC denetimli servo kontrol sistemi egitim setinin tasarimi ve uygulamasi. In: International Conference on Educational Sciences, Eastern Mediterranean University, June 23-25, Famagusta / North Cyprus, 455-462.

[20] Coskun, I. \& Isik, M. F. (2009). Design and application of the technical training set for PLC-based power supply unit developed for industrial applications. Procedia - Social and Behavioral Sciences, 1(1), 1658-1662. https://doi.org/10.1016/j.sbspro.2009.01.293

[21] Isik, M. F. \& Coskun, I. (2010). Servo control education tool for industrial applications. Electronics and Electrical Engineering, 10(106),159-164.

[22] Ioannides, M. G. (2004). Design and implementation of PLC-based monitoring control system for induction motor. IEEE Trans. Energy Conversion, 3(19), 469-478. https://doi.org/10.1109/TEC.2003.822303

[23] Birbir, Y. \& Nogay, H. S. (2008). Design and implementation of PLC based monitoring control system for three-phase induction motors fed by PWM inverter. Int. Journal of Systems Applications, Engineering \& Development, 2(3), 128-135.

[24] Isik, M. F. \& Haboglu, M. R. (2015). Design and implementation of real time monitoring and control system for robot arms used in industrial applications. In: $15^{\text {th }}$ International Conference on Robotics, Control and Manufacturing Technology, April 23-25, Kuala Lumpur / Malaysia, 33-37.

[25] Yang, A., Wu, J., Zhang, W., \& Kan, X. (2008). Research on asynchronous motor vector control system based on rotor parameters time-varying. WSEAS Transactions on Systems, 7(4), 384-393.

[26] Haiguo, P., Zhixin W., \& Huaqiang Z. (2009). Cooperative PSO based PID neural network integral control strategy and simulation research with asynchronous motor controller design. WSEAS Transactions on Circuits and Systems, 8(8), 696-708.

[27] Liu, J., Yao, L., Liu, X., An, Y., Guo, Y., \& Liang, Z. (2010). The teaching experiment system of SCADA in power system. In: Power and Energy Engineering Conference, March 28-31, Chengdu / China, 1-4. https://doi.org/10.1109/APPEEC.2010.5448621

\section{Contact information:}

\section{Mehmet Fatih ISIK}

Hitit University Faculty of Engineering

Electrical and Electronics Engineering Department

Cevreyolu Bv. No: 8 Corum / Turkey

mehmetfatih@hitit.edu.tr

\section{Mustafa Resit HABOGLU}

Hitit University Faculty of Engineering Mechanical Engineering Department Cevreyolu Bv. No: 8 Corum / Turkey mrhaboglu@gmail.com

\section{Cemal YILMAZ}

Gazi University Faculty of Technology Electrical and Electronics Engineering Department 06500 Teknikokullar, Ankara / Turkey cemal@gazi.edu.tr

\section{Ercan Nurcan YILMAZ}

Gazi University Faculty of Technology Electrical and Electronics Engineering Department 06500 Teknikokullar, Ankara / Turkey enyilmaz@gazi.edu.tr 